International Journal of Automotive and Mechanical Engineering (IJAME)

ISSN: 2229-8649 (Print); ISSN: 2180-1606 (Online); Volume 8, pp. 1121-1131, July-December 2013

(C) Universiti Malaysia Pahang

DOI: http://dx.doi.org/10.15282/ijame.8.2013.3.0091

\title{
INVESTIGATION OF ALUMINUM-STAINLESS STEEL DISSIMILAR WELD QUALITY USING DIFFERENT FILLER METALS
}

\author{
L. H. Shah, Z. Akhtar, and M. Ishak \\ Faculty of Mechanical Engineering, Universiti Malaysia Pahang, \\ 26600 Pekan, Pahang, Malaysia \\ Phone: +609-4246234 \\ E-mail: luqmanhakim@ump.edu.my
}

\begin{abstract}
Aluminum-stainless steel dissimilar welding processes yield unwanted disadvantages in the weld joint due to the large difference between the aluminum-stainless steel sheets' melting points and the nearly zero solid solubility between these two metals. Aluminum AA6061 and stainless steel SUS304 were lap-welded by using Metal Inert Gas (MIG) welding with aluminum filler ER5356 (Group 1) and stainless steel filler ER308LSi (Group 2). The effects of the welding voltage and type of filler metals used on the weld joints were studied. The welding voltage had a significant effect on the welding process, as higher voltage resulted in poorer appearance of the weld joint and led to defects for both groups, such as porosity and incomplete fusion. The microstructure for Group 1 joints shows enrichment of $\mathrm{Si}$ particles, which benefited the joint properties as it increased the strength of the metal. The stainless steel substrates that spread into the aluminum side are much greater in volume for Group 1 than for Group 2 joints. Meanwhile, the microstructure of Group 2 joints (using ER308LSi filler) consists of chromium carbide precipitation which yields a high hardness value, but a brittle structure. The hardness values of the welded seams in Group 1 and Group 2 range from 60 to $100 \mathrm{HV}$ and 160 to $230 \mathrm{HV}$, respectively. The fracture in the tensile test yielded the highest tensile strength of 104.4 MPa with aluminum fillers. The tensile strength of Group 1 joints ranging from 47.8 to $104.4 \mathrm{MPa}$ was collectively higher than Group 2 joints, between 20.24 to $61.76 \mathrm{MPa}$. Based on the investigation throughout this study, it can be concluded that the welding voltage of $18 \mathrm{~V}$ and aluminum filler ER5356 is the optimum filler in joining the dissimilar metals aluminum AA6061 and stainless steel SUS 304.
\end{abstract}

Keywords: MIG; dissimilar welding; aluminum; stainless steel; mechanical property.

\section{INTRODUCTION}

Welding is the method of joining two or more pieces of metal to make them act as a single piece. Welding has become one of the most important metalworking processes as almost everything made of metal is welded (Wang et al., 2006). Products of the welding industry include automobiles, airplanes, jet engines, etc. (Zhang \& Liu, 2011; Charde, 2012; Charde, 2013). Some of the advantages of welding are the low cost of this permanent joining method and the design flexibility it provides. Dissimilar welding is where weldments are made from metals of different compositions or thicknesses, or both. It is attracting attention nowadays, due to its many advantages, such as low manufacturing cost and the ability to reduce working operations (Saunders \& Wagoner, 1995; Kinsey, Viswanathan, \& Cao, 2001; Tusek, Kamous, \& Suban, 2001; Chan, 
Chan, \& Lee, 2003). Besides that, this type of joining offers the potential to utilize the advantages of different materials, which often produces a whole structure with unique mechanical properties. For example, hybrid structures of aluminum alloy and stainless steel are suggested for spacecraft, automotives and steamships to improve their fuel efficiency, increase their range and control air pollution by reducing weight (Zhang \& Liu, 2011; Fukumoto et al., 2000; Chan et al., 2003).

Even so, the dissimilar welding process yields unwanted disadvantages in the weld joint, such as brittle intermetallic reaction phase formation at elevated temperatures (Bang et al., 2012; Lin et al., 2010; Song et al., 2009; Dong et al., 2012). The defects that may occur in the specimens of this project are due to the large difference between the melting points of the steel-aluminum sheets, thermophysical properties, and the nearly zero solid solubility of iron in aluminum. Furthermore, differences in thermophysical properties, such as expansion coefficient, conductivity and specific heat, can lead to residual stresses after fusion welding (Dharmendra et al., 2011; Qiu, Iwamoto, \& Satonaka, 2009; Song et al., 2009; Lohwasser \& Chen, 2010). The weld joint is the most important area and is heavily affected by the selection of filler metals. Several researches have shown that the selection of the filler metal to use in the welding process is crucial to the weld joint, as some fillers add to the base metal elements to improve the properties of the weld metals (Dong et al. 2012; Shiri et al. 2012; Saeed et al. 2010). Dong et al. (2012) have proven that different types of aluminum and zinc fillers have a significant effect on the IMC formation and weld joint strength of aluminum-stainless steel weldments. However, no empirical study has been conducted to compare the effect of aluminum fillers and stainless steel fillers on aluminum-stainless steel metal inert gas (MIG) welding. This project looks into the effect of welding fillers on the quality of the weld joint and microstructure of MIGwelded aluminum-stainless steel sheets. The mechanical properties of the weld joints are also investigated.

\section{EXPERIMENTAL METHOD}

Materials used are AA6061 aluminum alloy and SUS304 stainless steel plates in 2.0 $\mathrm{mm}$ thickness. Both materials are commonly used in industry due to their high corrosion resistance and versatility (Lippold \& Kotecki, 2005; Mandal, 2005; Callister, 2000). The filler metals used are stainless steel based ER 308LSi and aluminum based ER 5356, with a diameter of $2.5 \mathrm{~mm}$ for both fillers. Table 1 represents the chemical composition of AA6061 and aluminum filler ER 5356 (Gomez de Salazar et al., 2003). The chemical composition for SUS 304 and stainless steel filler ER 308LSi is shown in Table 2 (Taban et al., 2012). All plates were cut to sizes of $110 \mathrm{~mm} \times 25 \mathrm{~mm}$ using an MVS/C 6/31 shearing machine with a maximum capacity of $209 \mathrm{kN}$.

Table 1. Chemical composition of AA6061 and ER 5356 (wt\%)

\begin{tabular}{lrlllllllc}
\hline & $\mathrm{Mg}$ & $\mathrm{Al}$ & $\mathrm{Si}$ & $\mathrm{Mn}$ & $\mathrm{Fe}$ & $\mathrm{Cu}$ & $\mathrm{Cr}$ & $\mathrm{Zn}$ & \multicolumn{1}{c}{$\mathrm{Ti}$} \\
\hline AA 6061 & 0.84 & 97.7 & 0.54 & 0.01 & 0.40 & 0.24 & 0.18 & 0.006 & 0.031 \\
ER 5356 & 4.5 & Bal. & 0.25 & 0.20 & 0.40 & 0.05 & 0.05 & 0.15 & 0.15 \\
\hline
\end{tabular}


Table 2. Chemical composition of SUS 304 and ER 308LSi (wt\%)

\begin{tabular}{cccccccccc}
\hline & $\mathrm{Cr}$ & $\mathrm{Ni}$ & $\mathrm{Mo}$ & $\mathrm{Cu}$ & $\mathrm{C}$ & $\mathrm{Si}$ & $\mathrm{Mn}$ & $\mathrm{P}$ & $\mathrm{Fe}$ \\
\hline SUS 304 & 18.36 & 9.23 & 0.07 & 0.08 & 0.051 & 0.76 & 0.97 & 0.027 & Bal \\
ER 308LSi & 20.0 & 9.79 & 0.10 & 0.10 & 0.02 & 0.76 & 1.51 & 0.03 & Bal \\
\hline
\end{tabular}

Aluminum and stainless steel were lap-welded using an MIG welding Migatronic 3000 Duo, where the aluminum sheets were placed above the stainless steel counterpart. Two different sets of specimens were fabricated during the welding process for the tensile test and for the microstructure as well as a hardness analysis. Figures 1 and 2 show schematic diagrams of the aluminum-stainless steel lap joints for the tensile test specimen and for the microstructure and hardness analysis, respectively. Figure 3 shows the schematic diagram of the experimental setup.

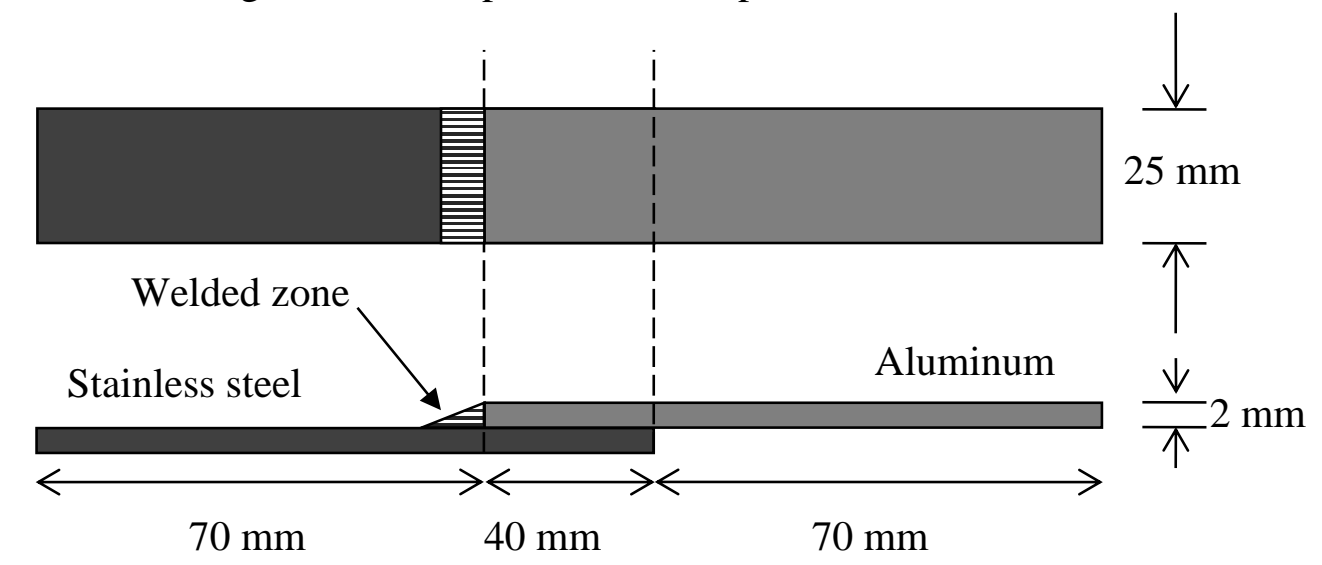

Figure 1. Schematic diagram of aluminum-stainless steel lap joint for tensile test specimen.

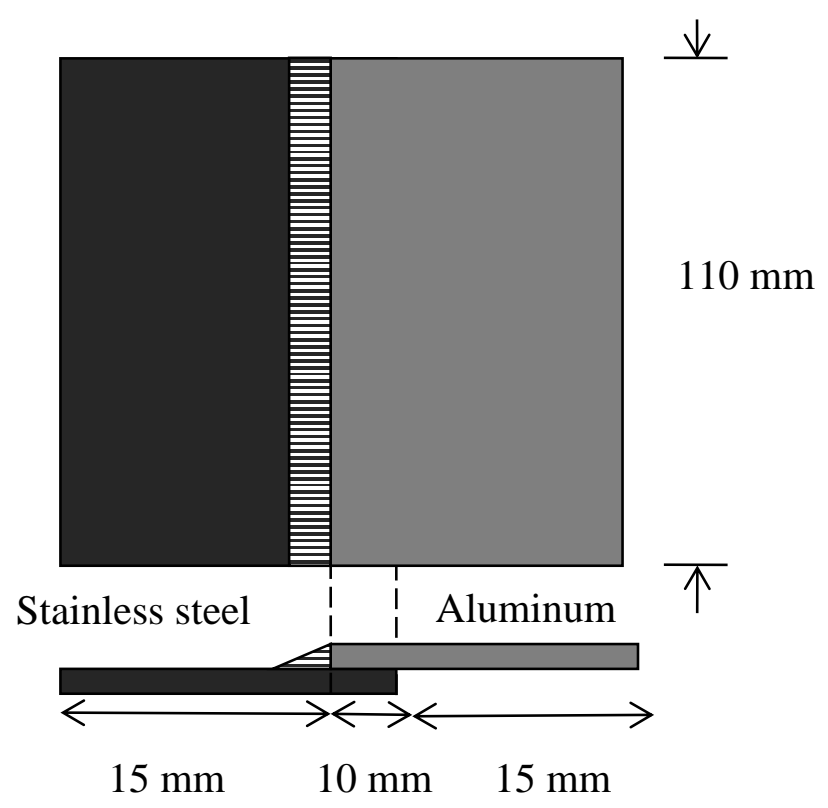

Figure 2. Schematic diagram of aluminum-stainless steel lap joint for microstructure and hardness analysis. 
The specimens were divided into two groups. Group 1 represents aluminumstainless steel joints using aluminum filler, while Group 2 represent aluminum-stainless steel joints using stainless steel filler. As well as the filler metal, the welding voltage was also varied. The varied welding parameters of the two groups are shown in Table 3. Through trial and error, it was found that the weldable voltage range to cater for both fillers in this particular setting was very limited, between 17 and $19 \mathrm{~V}$.

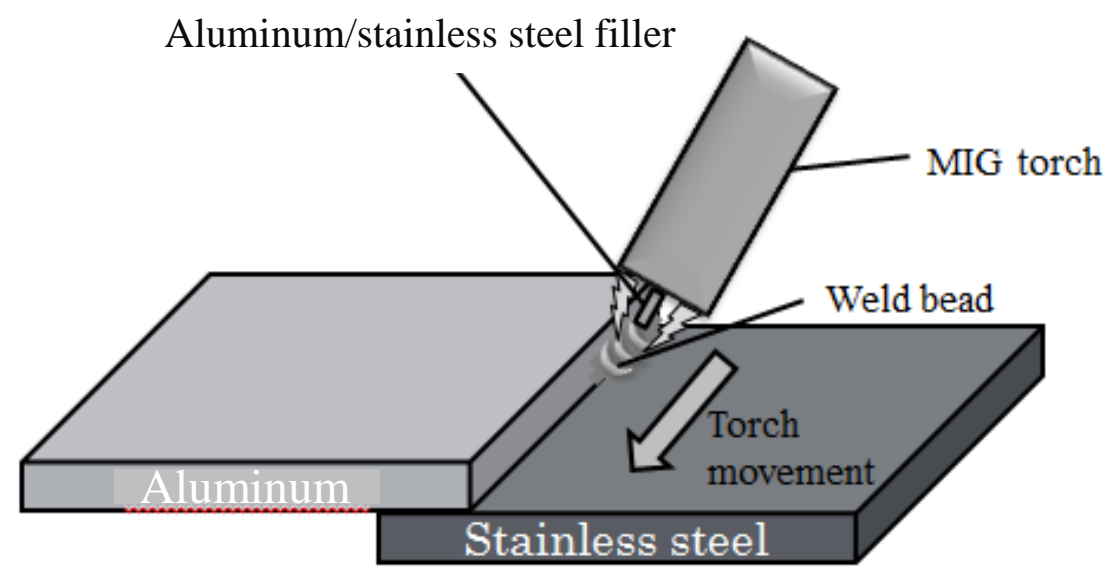

Figure 3. Schematic diagram of the experimental setup.

The specimens were mounted using a cold mounting machine and were manually ground in the longitudinal and latitudinal directions with a sequence of 240, 320,400 and 600 grit papers. To get a mirror-like surface finish, Forcipol 2V GrinderPolisher was used to polish the ground specimen. Etching of specimens at ambient temperature was performed to draw out the material microstructure for observation under the optical microscope as well as for scanning electron microscopy (SEM). Since dissimilar specimens require different etching solutions for the etching process, Keller's etchant and electrolyte etchant were separately dabbed using cotton buds and washed using distilled water on the aluminum and stainless steel surfaces respectively.

Table 3. Welding parameters for Group 1 and Group 2.

\begin{tabular}{ccc}
\hline Joint & Voltage $(\mathbf{V})$ & Filler metals \\
\hline Group 1 & 17 & \\
1 & 18 & ER 5356 \\
2 & 19 & ER 5356 \\
3 & & \\
Group 2 & 17 & ER 3356 \\
4 & 18 & ER 308LS \\
5 & 19 & ER 308LS \\
6 & &
\end{tabular}

The Vickers hardness test and tensile test were conducted to analyze the mechanical properties of the samples. The Vickers hardness profile across the base metals and fusion zone was observed using the Miyazu MMT-X7 hardness tester with $500 \mathrm{gf}$ for 10 seconds dwell time. On the other hand, the fracture behavior was analyzed 
using a Shimadzu Universal Testing machine with $100 \mathrm{kN}$ capacity. The tensile specimens were prepared with reference to ASTM D1002, namely for the lap shear test specimens. The gauge length and grip length for all specimens were $130 \mathrm{~mm}$ and 25 $\mathrm{mm}$ respectively. The tensile test was carried out at a temperature of $20^{\circ} \mathrm{C}$, at a crosshead speed of $1.3 \mathrm{~mm} / \mathrm{min}$.

\section{RESULTS AND DISCUSSION}

\section{Macrostructure and Microstructure Analysis}

Figure 4 shows the weld bead appearance of Group 1 samples (Figure 4(a)-(c)) and Group 2 samples (Figure 4(d)-(f)) made with different weld voltages. Some common welding defects can be seen, such as porosity and incomplete fusion. For Group 1, the spreading degree of the molten aluminum on the steel surface was limited (Zhang et al., 2011). This is due to the wide difference between the melting temperatures of aluminum (approximately $649^{\circ} \mathrm{C}$ ) and stainless steel (approximately $1538^{\circ} \mathrm{C}$ ). The aluminum melts and flows away well before the stainless steel has melted. This situation explains why the aluminum is just barely intact with the stainless steel surface and they are not soluble with each other. Based on observation of the macrostructure of all joints, the joints with welding voltage $18 \mathrm{~V}$ have the best appearance.
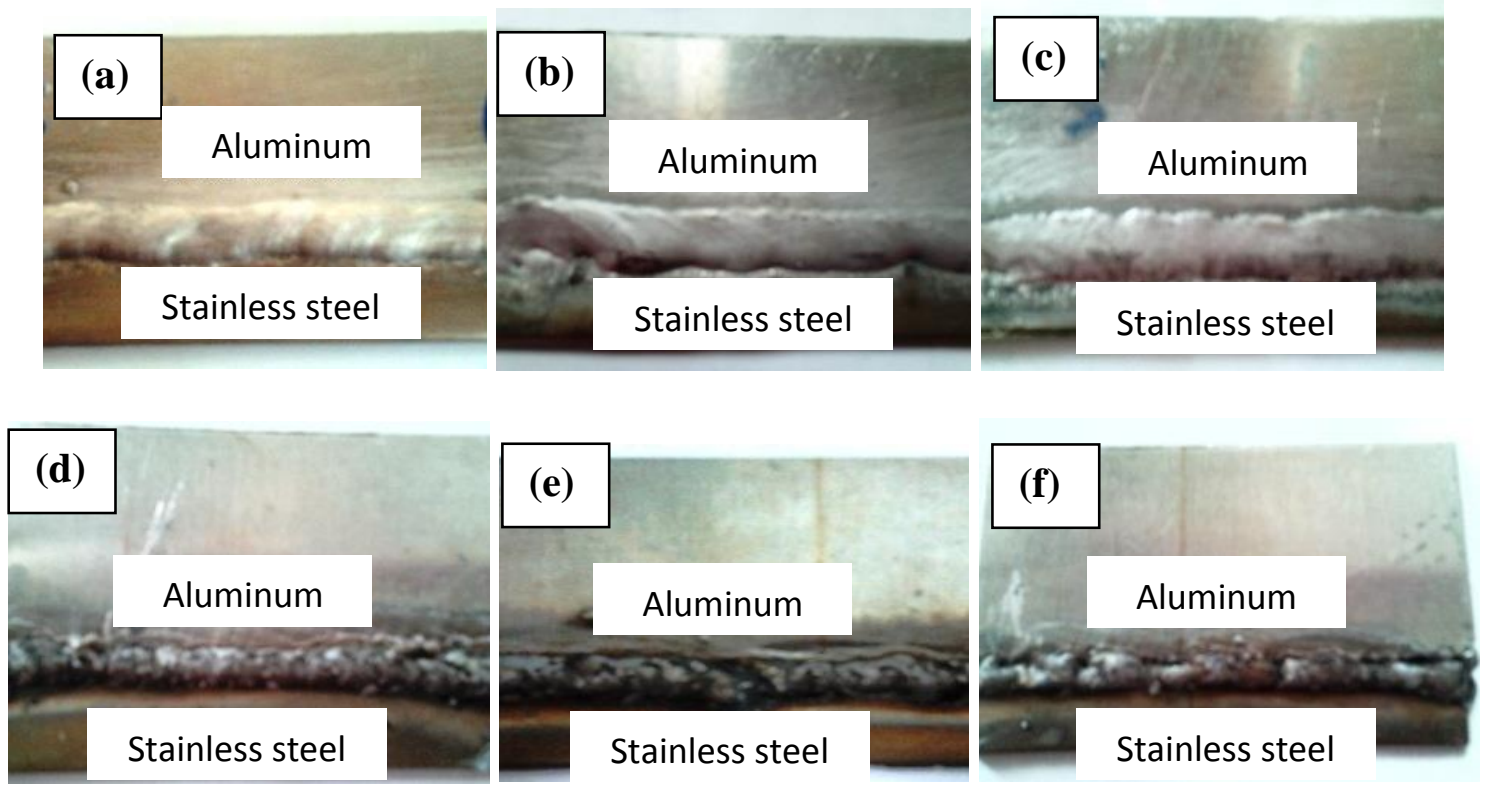

Figure 4. Appearance of weld joints for Group 1: (a) $17 \mathrm{~V} \mathrm{(b)} 18 \mathrm{~V}$ (c) $19 \mathrm{~V}$ and Group 2: (d) $17 \mathrm{~V} \mathrm{(e)} 18 \mathrm{~V}$ and (f) $19 \mathrm{~V}$, respectively.

On the other hand, the weld appearance in Group 2 is relatively poor compared to the Group 1 joints, as hot cracking occurs on the aluminum side. Since aluminum melts long before stainless steel does, this leads to the hot cracking and shrinkage of the aluminum through the cooling process. Figure 5 shows the cross-sections of Group 1 and Group 2. It is evident that the aluminum filler in Group 1 mixed very well with the aluminum sheet but not with the stainless steel one, whereas the stainless steel filler in Group 2 mixed very well with the stainless steel sheet but not with its aluminum counterpart. 


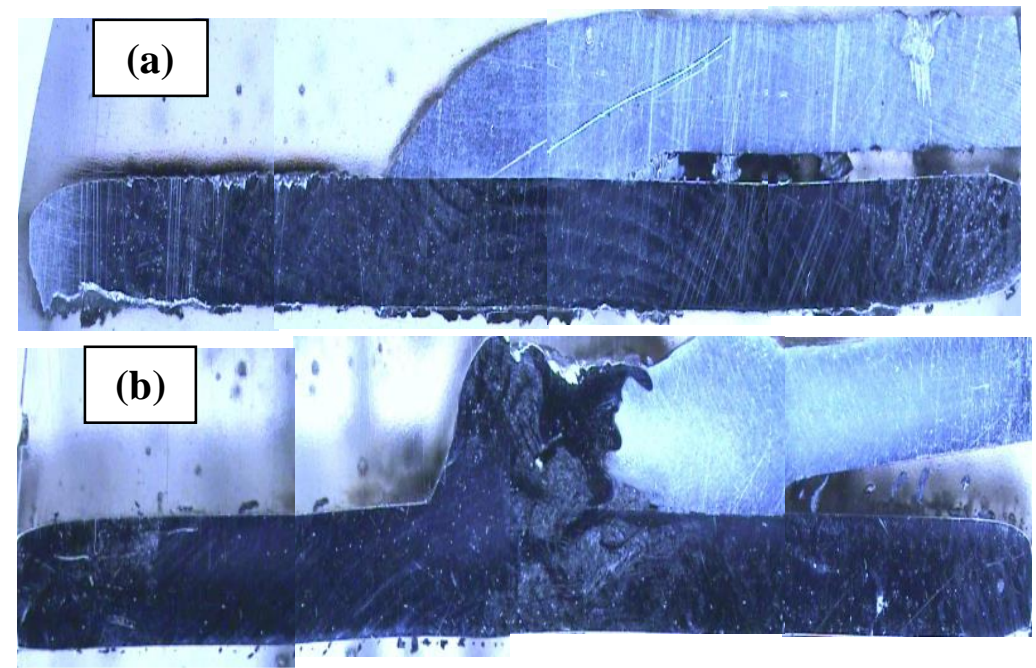

Figure 5. Cross-section of (a) Group 1 and (b) Group 2
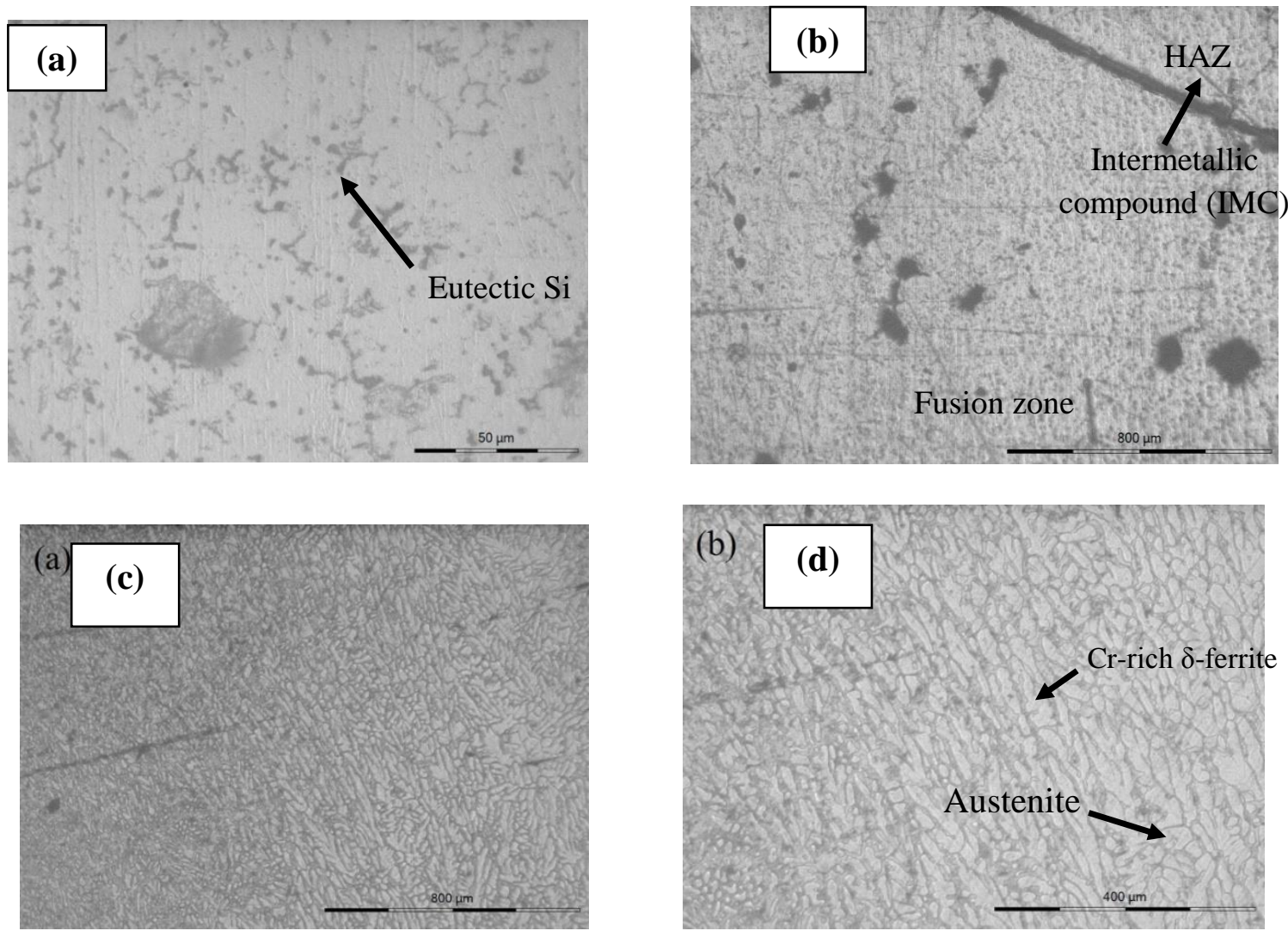

Figure 6. Metallographic photos of fusion zone with different scales for Group 1: (a) 50 $\mu \mathrm{m}$ (b) $800 \mu \mathrm{m}$ and Group 2: (c) $800 \mu \mathrm{m}$ (d) $400 \mu \mathrm{m}$

Figure 6 shows the metallographic photo of the fusion zone with varying scales for both groups. In Figure 6(a), enrichment of eutectic Si can be seen, since both the filler metal and the base metal aluminum contained a certain percentage of silicon. Like the grain size, smaller eutectic Si particles mean that the hardening agents are better dissolved, thus increasing the hardness of the joint. In addition, the existence of $\mathrm{Si}$ elements in the aluminum matrix helps the solubility and dissolution rate of $\mathrm{Fe}$ in the $\mathrm{Al}$ molten pool to increase significantly and prevent thick IMC formation (Song et al., 
2010) (Figure 6(b)). IMC is known to affect the crack sensitivity, ductility and strength of the joint. A thicker layer of this will result in more brittle joints and reduce the strength and hardness. Preheating or the existence of a secondary heat source other than the MIG torch such as a laser or TIG torch can be a means to suppress this IMC formation (Budkin, 2011; Bang et al., 2013; Powell et al., 2011; Thomy \& Vollertsen, 2012). On the other hand, Figure 6 (c)-(d) for Group 2 shows a different microstructure. Cr-rich $\delta$-ferrite (bcc) skeletal regions can be observed throughout the fusion zone, indicating a Type F (primary ferrite) stainless steel solidification. The outer portions of the dendrites having less $\mathrm{Cr}$ transform into an austenite (fcc) matrix. The calculated ferrite number for this composition is $18 \mathrm{FN}$. This type of solidification is also not sensitive to solidification cracking (Kou, 2003; Lippold \& Kotecki, 2005; Kotecki \& Siewert, 1992).

The stainless steel filler contains alloying addition chromium and traces of carbon. Chromium is a strong carbide former and a ferrite promoter. It is also the main component in the formation of the brittle IMC layers, which will have a detrimental effect on the aluminum-stainless steel joint strength, as is evident in the fracture test conducted below (Lippold \& Kotecki, 2005). During welding, carbon will combine with chromium to form chromium carbides at grain boundaries through the sensitization process (Kou, 2003). Though materials with such microstructures possess high strength, they also have brittle properties, which will be discussed in further detail in the mechanical property analysis.

\section{Mechanical Property Analysis}

The Vickers hardness pattern across the base materials and the welded seam is measured using a macrohardness tester. A total of 11 points were indented across the specimen in order to measure the hardness value of the joint. The hardness distribution profiles of aluminum-stainless steel joints for Group 1 and 2 are shown in Figure 7. For both groups, the base metal stainless steel and base metal aluminum area has an average hardness value range of 160-200 HV and 60-85 HV, respectively. For the aluminum filler welded seam, the average hardness value ranges between 60 and $100 \mathrm{HV}$, which is similar to base metal aluminum. As for the stainless steel filler, the average hardness value ranges between 180 and $230 \mathrm{HV}$. These values are higher than for the base metal stainless steel. The hardness value in the stainless steel filler welded seam (180-230 $\mathrm{HV}$ ) is acceptable, since it is in the range of the theoretical value of similar welding stainless steel joints (220-240 HV). From Figure 7(b) it can be seen that the hardness values in the welded seam are higher than the hardness of the base metal due to the addition of manganese, chromium and molybdenum in the fusion zone from the ER308LSi filler and due to refinement of the grain size.

It is also interesting to note that for both filler cases, almost all samples show a slight hardness decrease compared to the base metal counterparts in the heat affected zone (HAZ), i.e., the area between the welded seam and base metal. This indicates that there is not enough heat generated in the region during welding to impose microstructural change and grain refinement (Uzun et al., 2005; Borrisutthekul et al., 2010). 


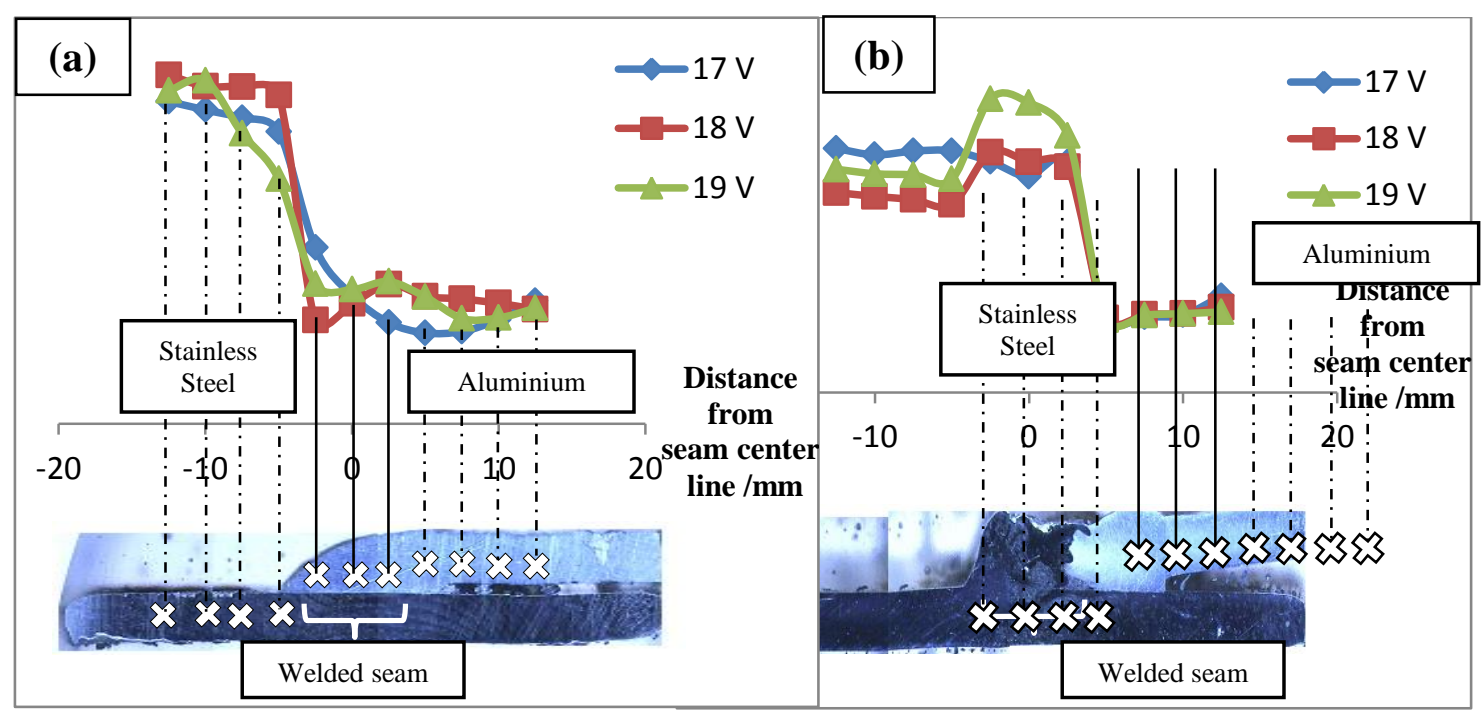

Figure 7. Hardness distribution of aluminum-steel joint for (a) Group 1 and (b) Group 2.

The tensile strength of joints obtained with different weld voltages is listed in Figure 8. For Group 1, the tensile strength of Joint No. 2 (18 V) reaches $104.4 \mathrm{MPa}$, which is higher than Joints No. 1 and No. 3, which have tensile strength values of 47.8 $\mathrm{MPa}$ and 88.6 MPa, respectively. As for Group 2, the tensile strength of Joint No. 5 (18 V) reaches $61.76 \mathrm{MPa}$, which is the highest value in the group. Joints No. 1 and No. 3 yielded tensile strength values of 20.24 MPa and 53.6 MPa, respectively. Since there has been no research that specifies the joining of stainless steel 304 and aluminum AA6061, the experimental value cannot be compared to the actual value of tensile strength for this joint. Thus, a comparison was made with a similar butt-welded welding aluminum joint (AA6061) for Group $1(163 \mathrm{MPa}$ ) and with a similar butt-welded welding stainless steel joint (SUS304) for Group 2 (550 MPa). The tensile strength values in the experiment are much lower due to insufficient solubility between the aluminum-stainless steel, which resulted in the decrease of tensile strength.

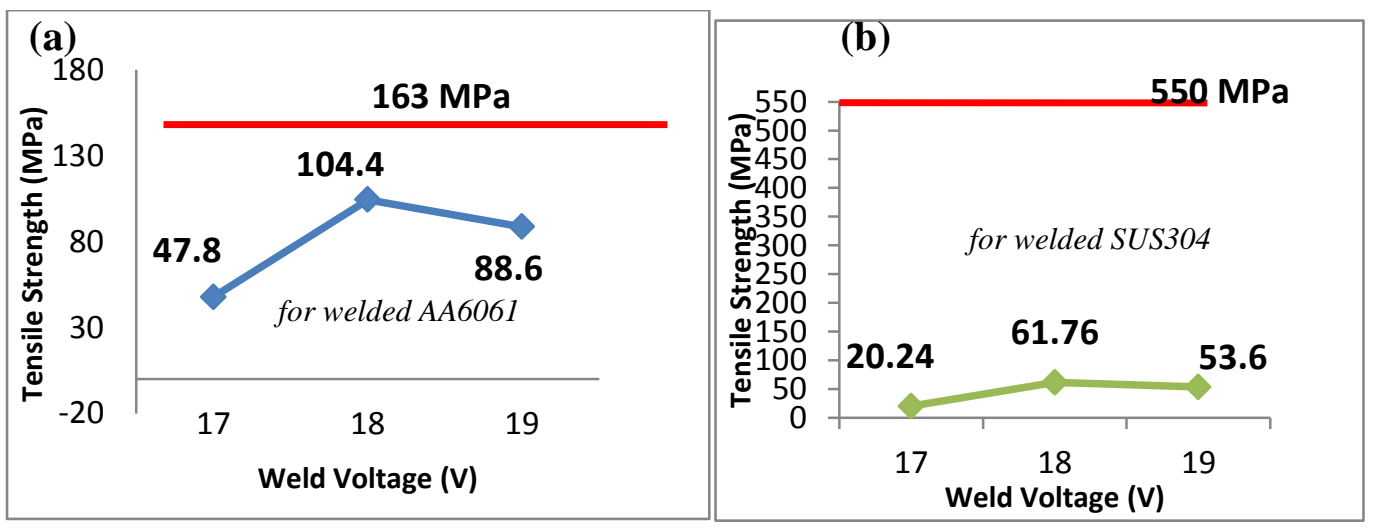

Figure 8. Tensile strength of the weld under different voltages for (a) Group 1 and (b) Group 2. 
Comparing the results for Group 1 and Group 2, aluminum filler welded seams show a much better tensile strength, despite their relatively low weld seam hardness. Upon inspection, it can be seen that for both cases, the fracture occurs in the region where the filler did not mix well, i.e., for Group 1 the fracture is between the aluminum filler and stainless steel, and for Group 2, the fracture is between the stainless steel filler and aluminum. This region is the weakest point in the joint in both cases. Since Group 1 yielded a much higher tensile strength than stainless steel, this shows that despite the high hardness value of the weld seam for Group 2, the weld seam region possesses brittle characteristics.

\section{CONCLUSION}

Dissimilar welding between aluminum AA 6061 alloy and stainless steel SUS 304 was lap-joined successfully by MIG welding with aluminum and stainless steel filler. The conclusions from this study can be summarized as follows:

i) The welding voltage had a significant effect on the welding process, as higher voltage resulted in poorer appearance of the weld joint and led to defects for both groups, such as porosity and incomplete fusion.

ii) The microstructure for Group 1 joints (using ER5356 filler) shows enrichment of Si particles, which benefited the joint properties by increasing the strength of the metal. The stainless steel substrates that spread into the aluminum side are much greater in volume for Group 1 than for Group 2 joints. Meanwhile, the microstructure of Group 2 joints (using ER308LSi filler) consists of chromium carbide precipitation which yields a high hardness value, but has a brittle structure.

iii) The hardness value of the welded seam in these joints ranges from 60 to 230 HV, with Group 2 joints having higher values than Group 1 up to $230 \mathrm{HV}$. The Vickers hardness values of Group 1 joints indicate that the welded seam has a similar value to the base metal aluminum and Group 2 joints show similar values to base metal stainless steel. The fractures in the tensile tests yielded the highest tensile strength of $104.4 \mathrm{MPa}$ with aluminum fillers (Group 1). The tensile strength of Group 1 joints ranging from 47.8 to 104.4 $\mathrm{MPa}$ were collectively higher than for the Group 2 joints, which was between 20.24 and $61.76 \mathrm{MPa}$.

iv) Based on the investigation throughout this study, it can be concluded that the welding voltage of $18 \mathrm{~V}$ and aluminum filler ER5356 is the optimum filler in joining dissimilar metal aluminum AA6061 and stainless steel SUS 304.

\section{ACKNOWLEDGMENT}

The author would like to thank Universiti Malaysia Pahang for the research funding.

\section{REFERENCES}

Bang, H., Bang, H., Jeon, G. H., Oh, I. H., \& Ro, C.S. (2012). Gas tungsten arc welding assisted hybrid friction stir welding of dissimilar materials A16061-T6 aluminum alloy and STS304 stainless steel. Materials and Design, 37, 48-55. 
Bang, H., Bang, H., Song, H., \& Joo, S. (2013). Joint properties of dissimilar Al6061T6 aluminum alloy/Ti-6\%Al-4\%V titanium alloy by gas tungsten arc welding assisted hybrid friction stir welding. Materials and Design, 51, 544-551.

Budkin, Y. V. (2011). Welding joints in dissimilar metals. Welding International, 25(7), 523-525.

Borrisutthekul, R., Mitsomwang, P., Rattanachan, S., \& Mutoh, Y. (2010). Feasibility of using TIG welding in dissimilar metals between steel/aluminium alloy. Energy Research Journal, 1(2), 82-86.

Callister, W. D. (2000). Material science and engineering: An introduction. New York: John Wiley.

Chan, S. M., Chan, L. C., \& Lee, T. C. (2003). Tailor-welded blanks of different thickness ratios effects on forming limit diagrams. Journal of Materials Processing Technology, 132, 95-101.

Charde, N. (2012). Characterization of spot weld growth on dissimilar joints with different thicknesses. Journal of Mechanical Engineering and Sciences, 2, 172180.

Charde, N. (2013). Microstructure and fatigue properties of dissimilar spot welds joints of AISI 304 and AISI 1008. International Journal of Automotive and Mechanical Engineering, 7, 882-899.

Dharmendra, C., Rao, K., Wilden, J., \& Reich, S. (2011). Study on laser weldingbrazing of $\mathrm{Zn}$ coated steel to $\mathrm{Al}$ alloys with a $\mathrm{Zn}$ based filler. Materials Science and Engineering A, 528, 1497-1503.

Dong, H., Hu, W., Duan, Y., Wang, X., \& Dong, C. (2012). Dissimilar metal joining of aluminium alloy to galvanized steel with $\mathrm{Al}-\mathrm{Si}, \mathrm{Al}-\mathrm{Cu}, \mathrm{Al}-\mathrm{Si}-\mathrm{Cu}$ and $\mathrm{Zn}-\mathrm{Al}$ filler wires. Journal of Materials Processing Technology, 212(2), 458-464.

Fukumoto, S., Tsubakino, H., Okita, K., Aritoshi, M., \& Tomita, T. (2000). Amorphization by friction stir welding between 5052 aluminium alloy and 304 stainless steel. Scripta Materialia, 42, 807-812.

Gomez de Salazar, J. M. \& Barrena, M. I. (2003). Dissimilar fusion welding of AA7020/MMC reinforced with $\mathrm{Al}_{2} \mathrm{O}_{3}$ particles: Microstructure and mechanical properties. Materials Science and Engineering: A, 352(1-2), 162-168.

Kinsey, B., Viswanathan, V., \& Cao, J. (2001). Forming of aluminium tailor welded blanks. Journal of Materials and Manufacturing, 110, 673-679.

Kotecki, D. J. \& Siewert, T. A. (1992). WRC-1992 constitution diagram for stainless steel weld metals: a modification of the WRC-1988 diagram. Welding Journal, 63(9), 282-288.

Kou, S. (2003). Welding metallurgy (2nd ed.). New Jersey: John Wiley.

Lakshminarayanan, A. K., Balasubramanian, V., \& Elangovan, K. (2009). Effect of welding processes on tensile properties of AA6061 aluminium alloy joints. International Journal of Advanced Manufacturing Technology, 40, 286-296.

Lin, S. B., Song, J. L., Yang, C. L., Fan, C. L., \& Zhang, D. W. (2010). Brazability of dissimilar metals tungsten inert gas butt welding-brazing between aluminum alloy and stainless steel with $\mathrm{Al}-\mathrm{Cu}$ filler metal. Materials and Design, 31, 2637-2642.

Lippold, J. C. \& Kotecki, D. J. (2005). Welding metallurgy and weldability of stainless steels. New Jersey: John Wiley.

Lohwasser, D. \& Chen, Z. 2010. Friction stir welding: From basics to applications. Cambridge: Woodhead.

Mandal, N. R. (2005). Aluminium welding. Kharagpur: Narosa. 
Powell, J., Lamas, J., Karlsson, J., Norman, P., Kaplan, A. F. H., \& Yanez, A. (2011). The sensitivity of hybrid laser welding to variations in workpiece position. Physics Procedia, 12, 188-193.

Qiu, R., Iwamoto, C. \& Satonaka, S. (2009). The influence of reaction layer on the strength of aluminium/steel joint welded by resistance spot welding. Materials Characterization, 60, 156-159.

Saeed, A. M., Hussain, Z., Badri, A., \& Ariga, T. (2010). The effect of welding parameters on the weldability of different materials using brazing alloy fillers. Materials and Design, 31(7), 3339-3345.

Saunders, F. I. \& Wagoner, R. H. (1995). The use of tailor-welded blanks in automotive applications - Simulation of Materials Processing: Theory, Methods and Applications. Rotterdam: Shen \& Dawson.

Shiri, S. G., Nazarzadeh, M., Sharifitabar, M., \& Afarani, M. S. (2012). Gas tungsten arc welding of CP-copper to 304 stainless steel using different filler metals. Transactions of Nonferrous Metals Society of China, 22(12), 2937-2942.

Song, J. L., Lin, S. B., Yang, C. L., \& Fan, C. L. (2009). Effects of Si addition on intermetallic compound layer of aluminium-steel TIG welding-brazing joint. Journal of Alloys and Compounds, 488, 217-222.

Taban, E., Dhooge, A., Kaluc, E., \& Deleu, E. (2012). Effect of the consumable on the properties of gas metal arc welded EN 1.4003-type stainless steel. Supplement to the Welding Journal, 213-221.

Thomy, C. \& Vollertsen, F. (2012). Laser-MIG hybrid welding of aluminium to steel Effect of process parameters on joint properties. Welding in the World, 56(5-6), 124-132.

Tusek, J., Kampus, Z., \& Suban, M. (2001). Welding of tailored blanks of different materials. Journal of Materials Processing Technology, 119, 180-184.

Uzun, H., Donne, C. D., Argagnotto, A., Ghidini, T., \& Gambaro, C. (2005). Friction stir welding of dissimilar A16013-T4 to X5CrNi18-10 stainless steel. Materials \& Design, 26(1), 41-46.

Wang, Z., Chen, Y., Nan, Z., \& Hu, Y. (2006). Study on welder training by means of haptic guidance and virtual reality for arc welding. Proceedings of International Conference on Robotics and Biomimetics, 954-958.

Zhang, H. \& Liu, J. (2011). Microstructure characteristics and mechanical property of aluminum alloy/stainless steel lap joints fabricated by MIG welding-brazing process. Materials Science and Engineering A, 528, 6179-6185. 